\title{
Limitations in Adult Orthodontics: A Review
}

\author{
Dinesh K Bagga
}

\section{ABSTRACT}

Adults seeking orthodontic treatment have been increased considerably over the years as society is gradually becoming more esthetic oriented. These adults have already completed growth of craniofacial complex and treatment modality of growth modification is not an option for them. Many biological and psychosocial factors associated with adults need a change in biomechanics and treatment approach than that in growing adolescents. The present article attempts to explore the limitations in adult orthodontics.

\section{Contact Author}

\section{Dr. Dinesh K. Bagga}

E-mail : drdkbagga2000@yahoo.co.in

Key words: Adult orthodontics

J Oral Health Comm Dent 2009;3(3):52-55

A $\mathrm{n}$ increased inflow of adult patients has been witnessed in orthodontic practice during recent times. Adult orthodontics requires a different approach to the treatment than treatment for growing adolescent individuals due to varied reasons. Lack of growth potential makes growth modification procedures not applicable to adults and imposes limitations to certain tooth movements. Periorestorative problems, multiple extractions, other oral diseases, systemic problems, aging of the tissues, different psychosocial factors need to be considered while formulating appropriate individualized treatment plan. The complex interaction of these factors leads to a much different approach for adult orthodontics.(1)

\section{Limiting Factors \& Treatment Considerations}

An adult patient requires a different treatment approach from adolescents due to following limiting factors.

\section{Lack of growth}

Growth modification appliances cannot be used. Orthodontic treatment involves tooth movement, surgical correction of skeletal anomaly and dental camouflage. Overbite correction should be carried out by intrusion of anterior teeth, not by extrusion of posterior teeth, $(2,3)$ because the latter will encroach in the freeway space due to lack of vertical growth stressing the TMJ muscles and result in downward and backward movement of the mandible, which thereby tend to relapse due to instability. If individual tooth extrusion is required to level the associated vertical bone defect, the tooth is occlusally equilibrated.(4)

\section{Physiological age changes of varying degree}

Though success of osseointegration of oral implants in older and younger adults has been shown to be independent of increasing age(5) and bone healing of extraction socket was found unaffected by increasing age in an earlier study,(6) but a recent has shown that bone graft preparations (decalcified freeze-dried bone) from donors above 50 years had remarkably less osteogenic potential as compared to that from younger donors.(7) Cortical bone becomes more dense $(8,9)$ Haversian canals increase in size making the bone porous. Spongy bone is decreased with increasing age leading to change in the structure from honeycomb appearance to lace like network.(10) Bone volume decreases either by an increase in resorptive surfaces and osteoclastic activity(11) or by a decrease in the fraction of true forming surfaces.(12) With increasing age, this negative balance of bone leads to thinning of trabeculae altering the trabecular plates into trabecular spicules, thereby resulting in decrease of physical properties of bone making it more vulnerable to perforation due to osteoclastic resorption activity. Adult bone is also found less reactive to mechanical forces and risk of loss of attachment as well as bone loss is much more with mild gingival infections as compared to children and adolescents.(13) Marginal bone loss appears to be age related.(14) It may also occur due to periodontal disease. Occlusal function affects both the quantity and quality of the 
lamina dura and surrounding bone. Teeth without antagonist in the opposite arch show disuse dystrophy in their supporting bone.(15)

Age changes in periodontal ligaments are also seen. Decreased number of fibroblasts with more irregular structure, decreased organic matrix production and epithelial cell rests and increased amounts of elastic fibres have been reported to occur in periodontal ligaments with increasing age. Gingival connective tissue presents with a coarser and denser in structure with an increased collagen content due to increased collagen stabilization caused by changes in the macro-molecular conformation thereby resulting in increased rate of conversion of soluble to insoluble collagen, increased mechanical strength and increased denaturing temperature. Gingival recession (migration of junctional epithelium) is a physiological process, which occurs with simultaneous increase in the width of the attached gingival due to passive eruption of teeth to maintain occlusal contact with antagonist following loss of tooth surface from attrition.

Light forces are used due to varied reasons. Firstly, initially it takes longer time (delayed response) due to reduced cellular activity in adults.(16,17) Secondly, bone loss at alveolar crest due to aging or periodontal disease leads to apical shift of centre of resistance increasing the likelihood of tipping than bodily movement necessitating low force and large moment ratio. $(18,19)$ Thirdly, dense cortical bone and decreased periodontal width may lead to root resorption. $(20,21,22)$ Retraction force has a larger extrusive force component if the marginal bone loss is most pronounced, hence light continuous intrusive force should be maintained during retraction in such cases.

The delayed response to mechanical stimulus, is suggested to be caused by insufficient source of preosteoblasts. Norton(8) suggested that reduced vascularization with increasing age might also explain supply of insufficient amount of preosteoblasts (progenitor cells for bone formation). Rate of tooth movement in adults is similar to that in adolescents after delayed initial tissue reaction, when the tooth movement is much slower in adults than that in adolescents.(23) Total treatment time remains to be almost same for both adults and adolescents if good cooperation is achieved from an adult patient, which makes up for initial slower tooth movement.(23) Prolonged retention is required due to reduced cellular activity thereby increase in lag time to form bone in adult patients.

\section{Psychosocial factors}

Patient may have high expectations and hesitation in accepting visibility of orthodontic appliances. For esthetic reasons, patient may demand ceramic brackets or lingual orthodontics. Patient must be informed about the limitations of the treatment.

\section{Periorestorative problems}

Closure of old extraction site may be difficult especially in molar region.(24) It may need uprighting to open the space mesially to receive prosthesis.

While bonding, special considerations may be required due to presence of restorations such as porcelains and metallic surfaces.(25) Excess adhesive around orthodontic attachments should be removed as surface roughness of adhesive attracts more plaque retention. Strict oral hygiene procedures must be reinforced as patients with periodontal problems may have various difficult areas to clean. All restorations must be properly polished to reduce the tendency of plaque retention. Stainless steel ligatures may be preferred to elastomeric modules due to less retentive to plaque.(26)

Quantitative and qualitative changes in bone and compromised periodontal support and missing tooth may need special consideration to plan anchorage.(27) Headgears may not be acceptable to an adult due to esthetic reasons. Hence intraoral anchorage devices such as palatal arches and controlled forces are used. Microimplants can also be used to avoid dependence on teeth for anchorage.

Choice of extraction for orthodontic treatment may be affected by periorestorative problems or already extracted tooth.

Occlusion achieved in adults, are stable in a healthy patient but compromised periodontal status may need permanent retention. $(28,29)$

Adult patients have many preexisting conditions that are usually not present in adolescent patients. Hence, additional treatment objectives are established at the start of the treatment. Though acceptable esthetics is an integral part of treatment goal, but function, stability and health of dentition is given paramount importance. Additional treatment objectives(1) are determined to facilitate and improve effectiveness of periorestorative treatment by:

- Improving axial inclination of teeth, thereby improving root positioning with sufficient bone between roots for good vascular supply and proper contact area;

- Achieving parallelism of abutment teeth to minimize tooth cutting for fabrication of prosthesis;

- Most favorable distribution of abutment teeth to receive prosthesis for better stability;

- Uprighting and extrusion of posterior teeth with occlusal equilibration sometimes followed by endodontic treatment to improve vertical osseous defects and crown root ratio;

- Forced extrusion of teeth damaged upto one third of cervical line to provide better support at the margin of the prosthesis;

- To restore functional occlusion keeping in mind existing skeletal relationship rather than aiming for Andrew's six keys to normal occlusion;

- Achieving better lip support for flaccid \& long upper lip by maintaining anterior teeth in slight procumbent position 
with correction of overjet by proclining \& maintaining lower incisors in more procumbent position than normal position to avert wrinkles around the lips; \& restoring vertical dimension with bite plate before placing prosthesis in bite collapse.

\section{TMD}

Adult patient may seek the orthodontic treatment due to TMD and there is a higher risk of developing TMD in adult patients without TMD not related to orthodontic treatment. Hence, adult patient needs a thorough check up for the signs of TMD and he needs to be explained about the risk of developing TMD not necessarily related to orthodontic treatment and also limitations of orthodontic treatment in the management of TMD. $(18,30)$

\section{Signs of root resorption or vulnerability to root resorption}

Adult patient must be informed about the risk of root resorption and thoroughly evaluated for the susceptibility to root resorption.(22,31) All measures should be taken to manage root resorption.

Before starting orthodontic treatment, the patient must be carefully evaluated for systemic diseases, periorestorative problems, TMD and vulnerability to root resorption apart from routine diagnostic procedure. All the systemic and dental diseases should be appropriately managed with interdisciplinary approach at the start of orthodontic treatment. Adult orthodontics often requires interdisciplinary approach to deliver efficient treatment outcome.

\section{Conclusion}

In recent times, more focused attention is paid to better understand the limitations of adult orthodontics. An individualized appropriate treatment plan needs to be formulated for an adult patient on the basis of careful evaluation of a complex interaction of various biological, psychosocial and mechanical factors.

\section{THE AUTHORS}

\section{Dr. Dinesh K. Bagga}

BDS, MDS

Professor \& Head

Deptt. of Orthodontics \& Dentofacial Orthodpaedics,

I.T.S. Centre for Dental Studies \& Research,

Murad Nagar, Ghaziabad (UP)

\section{References}

1. Vanarsdall RL, Musich DR. Adult orthodontics: Diagnosis and treatment. In: Graber TM, Vanarsdall RL, Vig KWL (eds). Orthodontics : Current principles and techniques. $4^{\text {th }}$ edition, St Louis: Mosby, 2005.

2. Bishara SE. Textbook of orthodontics. WB Saunders Co, 2001.
3. Houston WJB. Mandibular growth rotations- their mechanisms and importance. Eur J Orthod 1988;10:369-373.

4. Kokich V. The role of orthodontics as an adjunct to periodontal therapy, In: Newman MG, Takei HH, Carranza FA, eds. Clinical periodontology, 9 $^{\text {th }}$ edn, Philadelphia, WB Saunders Co, 2002.

5. Bryant SR, Zarb GA. Osseointegration of oral implants in older and younger adults. Int J Oral Maxillofac Implants 1998;13:492499.

6. Amler $\mathrm{MH}$. Age factor in human alveolar bone repair. $J$ Oral Implantol 1993;19:138-142.

7. Schwarz Z, Somers A, Mellonig JT, Carnes DL Jr, Dean DD, Cochran DL, Boyan BD. Ability of commercial demineralized freeze-dried bone allograft to induce new bone formation is dependent on donor age but not gender. J Periodontol 1998; 69:470-478.

8. Norton LA. The effect of aging cellular mechanisms on tooth movement. Dent Clin North Am 1988;32:437-446.

9. Ringe JD, Rehpenning W, Steinhagen-Thiessen E. Increasing skeletal involution in the elderly? Mech Ageing Dev 1985;29:8388.

10. Melsen B. Limitations in adult orthodontics. In: Melsen B (ed). Current controversies in orthodontics. Quintessence Publishing Co, 1991.

11. Jowsey J, Phil D, Kelly PJ, Riggs BL, Bianoco AJ Jr, Scholz DA, et al. Quantitative microradiographic studies of normal and osteoporotic bone. J Bone Joint Surg 1965;47:785-806.

12. Melsen F, Mosekilde L. The role of bone biopsy in the diagnosis of metabolic bone disease. Orthop Clin North Am 1981;12:571602.

13. Boyd RL, Leggott PQ, Quinn RS, et al. Periodontal implications of orthodontic treatment in adults with reduced or normal periodontal tissues versus those of adolescents. Am J Orthod Dentofacial Orthop 1989;96:191-198.

14. Shei O, Waerhaug J, Lovdal A, Arnulf A. Alveolar bone loss as related to oral hygiene and age. J Periodontol 1959;26:7-16.

15. Picton DCA. The effect of external forces on the periodontium. In: AH Melcher, WH Bowen (eds) Biology of the periodontium. 363-419, New York, Academic Press, 1969.

16. Bond JA. The child versus the adult. Dent Clin North Am 1972;16:401-412.

17. Reitan K. Tissue reaction as related to the age factor. Dental Record 1954;74:271-279.

18. Proffit WR, Fields HW, Sarver DM. Contemporary Orthodontics. $4^{\text {th }}$ Ed, St Louis, Mosby, 2007.

19. Williams S, Melsen B, Agerbaek N, Asboe V. The orthodontic treatment of malocclusion in patients with previous periodontal disease. Br J Orthod 1982;9:178-84.

20. Reitan K. Effects of force magnitude and direction of tooth movement on different alveolar bone types. Angle Orthod 1964;34(4):244-55.

21. Reitan K. Initial tissue behavior during apical root resorption. Angle Orthod 1974;44:68-82.

22. Mirabella AD, Artun J. Risk factors for apical root resorption of maxillary anterior teeth in adult orthodontic patients. Am J Orthod Dentofac Orthop 1995;108:48-55. 
23. Dyer GS, Harris EF, Vaden JL. Age effects on orthodontic treatment: adolescents contrasted with adults. Am J Orthod Dentofac Orthop 1991;100:523-30.

24. Hom BM, Turley PK. Effects of space closure of the mandibular first molar area in adults. Am J Orthod Dentofac Orthop 1984;105:25-34.

25. Zachrisson BU, Buyukyilmaz T. Recent advances in bonding to gold, amalgam and porcelain. J Clin Orthod 1993;27:661-75.

26. Forsberg CM, Brattstrom V, Malmberg E, Nord CE. Ligature wires and elastomeric rings: two methods of ligation and their association with microbial colonization of Streptococcus mutans and Lactobacilli. Eur J Orthod 1991;13:416-420.

27. Ong MA, Wang HL, Smith FN. Interrelationships between periodontics and adult orthodontics. J Clin Periodontol 1998;25:271-277.

28. Harris EF, Vaden JL, Dunn KL. Effects of patient age on post orthodontic stability in Class II, division 1 malocclusion. Am J Orthod Dentofac Orthop 1994;105:25-34.

29. Kahl-Nieke B. Retention and stability considerations for adult patients. Dent Clin North Am 1996;40:961-994.

30. McNamara JA, Seligman DA, Okeson JP. Occlusion, orthodontic treatment and temporomandibular disorders: a review. J Orofacial Pain 1995;9:73-90.

31. Malmgren $O$, Levander E. Minimizing orthodontically induced root resorption. In Graber TM, Eliades T, Athanasiou AE (eds). Risk management in orthodontics: Experts' guide to malpractice. Quintessence Publishing Co, 2004. 